\title{
Comparison of Electric Vehicle's Energy Consumption Factors for Different Road Types
}

\author{
Enjian Yao, ${ }^{1,2}$ Zhiqiang Yang, $^{1,2}$ Yuanyuan Song, ${ }^{2}$ and Ting Zuo ${ }^{2}$ \\ ${ }^{1}$ MOE Key Laboratory for Urban Transportation Complex Systems Theory and Technology, Beijing Jiaotong University, \\ Beijing 100044, China \\ ${ }^{2}$ School of Traffic and Transportation, Beijing Jiaotong University, Haidian District, Beijing 100044, China
}

Correspondence should be addressed to Zhiqiang Yang; 12120938@bjtu.edu.cn

Received 30 September 2013; Revised 23 November 2013; Accepted 5 December 2013

Academic Editor: Huimin Niu

Copyright (C) 2013 Enjian Yao et al. This is an open access article distributed under the Creative Commons Attribution License, which permits unrestricted use, distribution, and reproduction in any medium, provided the original work is properly cited.

\begin{abstract}
Energy-optimal route planning for electric vehicle (EV) is highly required for the wide-spread use of EV, which is hindered by limited battery capacity and relative short cruising range. Obtaining the cost for each link (i.e., link energy consumption) in road networks plays a key role in energy-optimal route planning process. The link energy consumption depends mainly on energy consumption factor, which is related to not only vehicle speed but also road type. This study aims to analyze the difference of EV's energy consumption factors for different road types. According to the floating car data (FCD) collected from the road network in Beijing, the vehicle specific power (VSP) distributions under different average travel speeds for different road types are analyzed firstly, and then the EV's energy consumption rates under different VSP-Bins are calculated. By using VSP as an intermediate variable, EV's energy consumption factor models for different road types are established and the difference of EV's energy consumption factors is analyzed. The results show that road type-based energy consumption factor should be used in EV's energy-optimal route planning process.
\end{abstract}

\section{Introduction}

Recently, to cope with the problem of pollutant emissions and energy consumption caused by gasoline and diesel powered vehicles, increasing attention has been paid to EVs due to the advantages of zero-emission during use, low noise, and high energy efficiency. However, the relative short cruising range has become one of the main obstacles to the development and wide-spread use of EVs [1]. Some intelligent transportation systems (ITS) solutions such as energy-efficient route planning and charging facilities guidance systems are proposed to help EV drivers to optimize travel route and find charging station timely, which are expected to alleviate the restrictions resulted from the relative short cruising range of EVs. Estimating EV's energy consumption accurately is a prerequisite in route planning and navigation systems [2-4]; therefore it is of great significance to estimate EV's energy consumption.

Many researches on EV's energy consumption estimation are based on ideal running status, whose results cannot reflect the effect of the actual vehicle running status. Physicallybased methods, which take into account vehicle driving parameters (i.e., average travel speed), are usually used in modeling fuel consumption of gasoline and diesel powered vehicles [5]. In these models, VSP is introduced as an intermediate variable for the ability to build the relationship between energy consumption and vehicle microscopic driving parameters (i.e., instantaneous speed and acceleration). However, due to the difficulty in collecting the data for reflecting urban roads' real driving situation, existing researches scarcely take the difference of VSP distributions for different road types into consideration. A great many practices have proved that energy consumption varies greatly in different road types even when vehicles travel at a fixed average speed because the frequency and range of acceleration and deceleration are always different. Therefore, in order to estimate the EV's energy consumption for different road types with high accuracy, this paper attempts to establish energy consumption factor models for different road types and make a comparison among different road types. 
In the research field of EV's energy consumption models, energy consumption is usually equal to the integral of power of battery times the time, but this method fails to reflect the influence of running status on energy consumption. Some studies have already been done on how the influence of running status on energy consumption is presented [6]. For macroscopic models, vehicle average travel speed is always used as the independent variable and the speed correction factors are used to adjust the energy consumption factors for specific facility types [7]. However, it is questionable whether this approach can reflect the effects of various operation modes, such as frequent acceleration, deceleration, and idling on urban roads [811].

Motivated by the challenge associated with the preceding problem, related researches on the models which estimate EV's energy consumption with microscopic driving parameters as input have been conducted extensively. In the development of microscopic models, some researchers incorporate the parameters of instantaneous speed and acceleration. Yao et al. [12] establish a set of electricity consumption rate models and gasoline consumption rate models with instantaneous speed and acceleration as input parameters, to explore the relationship between the EV penetration and the reduction of energy consumption. Hansen et al. [13] and Zachariadis and Samaras [14] develop speed/acceleration matrices that provide fuel consumption per unit time for each combination of instantaneous speed and acceleration. In the VT-Micro model, Ahn et al. [15] use the combination of linear, quadratic, and cubic speed and acceleration terms for the model development by using the regression method. However, it is not realistic to expect that such a substantial number of microscopic driving parameters are always available in most current traffic information systems.

Other researches utilize VSP in the modeling of energy consumption. The VSP $(\mathrm{kw} / \mathrm{t})$, which is defined as the instantaneous power per unit mass of the vehicle [16], is verified to have direct physical interpretation of and strong statistical correlations with energy consumption [17]. After the first application by Jiménez-Palacios [16], VSP has been further developed and applied by other researchers in the area of fuel consumption modeling [18]. By analyzing the second-by-second data of fuel vehicle activities from floating cars and the on-road fuel consumption, Song and Yu [19] point out that VSP distribution in a traffic network determines the fuel consumption per unit time, and further, the combination of VSP distribution and average travel speed determines the fuel consumption per unit distance. In their studies, an approach for evaluating the fuel efficiency of road traffic is proposed on the basis of the characterization of VSP distribution and average travel speed from second-by-second data. Yao and Song [20] establish fuel consumption and emission models for light-duty gasoline vehicle, midduty diesel vehicle, and heavy-duty diesel vehicle separately based on vehicle average travel speed by using VSP as an intermediate variable. Liu and Yu [21] collect a mass of floating car data, analyze the VSP distributions for different road types in Beijing, respectively, and then provide

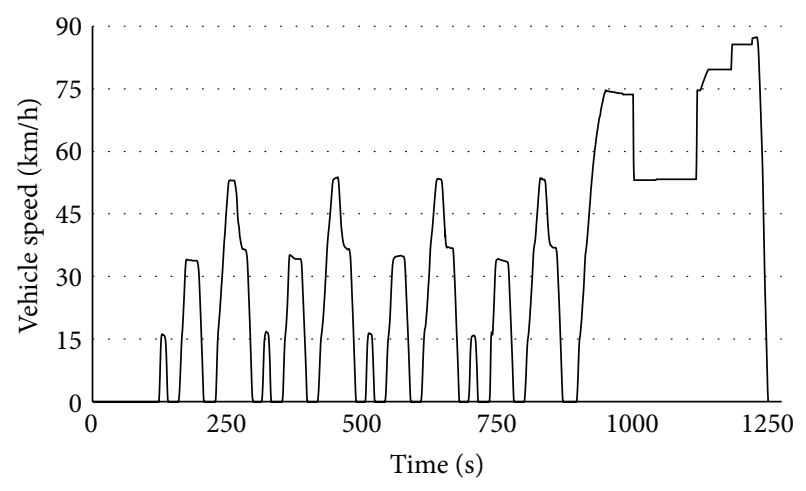

FIgURE 1: Driving cycle of data collection.

speed correction factors for proposed fuel consumption and emission models. Although the researches about fuel consumption are quite mature, there are almost no studies on the EV's energy consumption models for different road types.

The remaining part of this paper is organized as follows. The data utilized in modeling are introduced in Section 2.1 and a method of binning VSP is introduced in Section 2.2. The procedure of modeling EV's energy consumption is described in Section 2.3. In Section 3, a comparison of the VSP-Bin distributions for different road types is given, and then EV's energy consumption factor models for different road types are provided, respectively, and compared. The conclusions are given in Section 4 finally.

\section{Energy Consumption Factor Models}

This paper attempts to establish EV's energy consumption models for different road types, respectively. Urban roads in this paper are classified into express way, arterial road, secondary road, and branch. The influence of acceleration and deceleration on EV's energy consumption is reflected by comparing the VSP-Bin distributions for different road types. The energy consumption factor model for each road type is established, respectively, in which, instead of microscopic driving parameters, average travel speed, which is available in most current traffic information systems, is used as independent variable and VSP is used as intermediate variable.

2.1. Data Source. The data used in calculating the energy consumption rates under different VSP-Bins are collected from chassis dynamometer test of a light-duty EV based on the New European Driving Cycle (NEDC) as shown in Figure 1, in which instantaneous speed, acceleration, and battery output power are provided. The data used in analyzing VSP-Bin distributions for different road types are the floating car data collected from the road network in Beijing, in which speed and acceleration per second are provided. Figure 2 shows the test road network in Beijing, while Table 1 and Figure 3 summarized the data sample sizes and the speed distribution for different road types, respectively. 


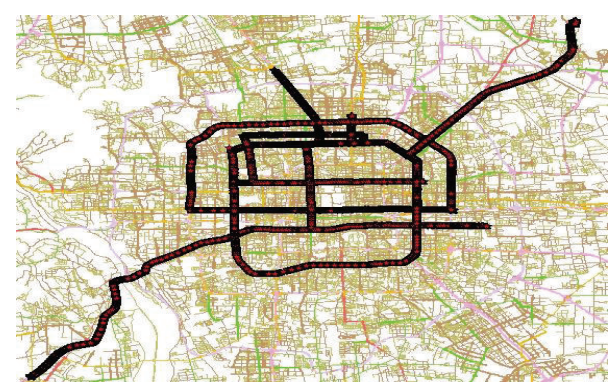

FIGURE 2: The test road network in Beijing.

TABLE 1: The data sample sizes for different road types.

\begin{tabular}{lc}
\hline Road type & Sample size \\
\hline Express way & 11378 \\
Arterial road & 4674 \\
Secondary road & 8853 \\
Branch & 5373 \\
\hline
\end{tabular}

2.2. Vehicle Specific Power. In this paper, simplified formula is used for the VSP calculation of a light-duty vehicle for various road types, as shown in the following [17]:

$$
\mathrm{VSP}=v \times(1.1 \times a+0.132)+0.000302 \times v^{3},
$$

where $v$ refers to the vehicle speed, $\mathrm{m} / \mathrm{s}$, and $a$ refers to the vehicle acceleration, $\mathrm{m} / \mathrm{s}^{2}$.

The VSP for each record from the chassis dynamometer test is calculated according to formula (1), and these VSP values are discrete. The characteristics of EV's energy consumption change greatly under different running status. In this paper, VSP is divided into different VSP-Bins by an interval of $1 \mathrm{kw} / \mathrm{t}$ as described in formula (2), so any running status could be modeled on the basis of calculating the time spent in each VSP-Bin [22]. By examining the VSP values of all 48976 records, it is found that 48959 (99\%) records fall into -30 to $30 \mathrm{kw} / \mathrm{t}$, which means the VSP range from -30 to $30 \mathrm{kw} / \mathrm{t}$ covers most the running status in the chassis dynamometer test. In particular, VSP $=0$ is set as a single VSP-Bin in this paper because the accuracy of the energy consumption rate diminishes if VSP $=0$ belongs to the bin $(0$, 1] or $[-1,0)$ as the size of the sample is relatively large when $\mathrm{VSP}=0$ :

$$
\begin{aligned}
& \text { VSP-Bin } \\
& = \begin{cases}n, & \forall: \operatorname{VSP} \in[n, n+1) \quad(n=-30,-29, \ldots,-1) \\
0, & \mathrm{VSP}=0 \\
n, & \forall: \operatorname{VSP} \in(n-1, n] \quad(n=1,2, \ldots, 30) .\end{cases}
\end{aligned}
$$

2.3. Modeling Methodology. After binning the VSP, the average energy consumption rate for each VSP-Bin is calculated. In order to build the connection between energy consumption rate and average speed, the second-by-second floating car data collected from the urban road in Beijing are divided into traveling segments by the interval of $60 \mathrm{~s}$, and each segment is characterized with its average travel speed. Then,

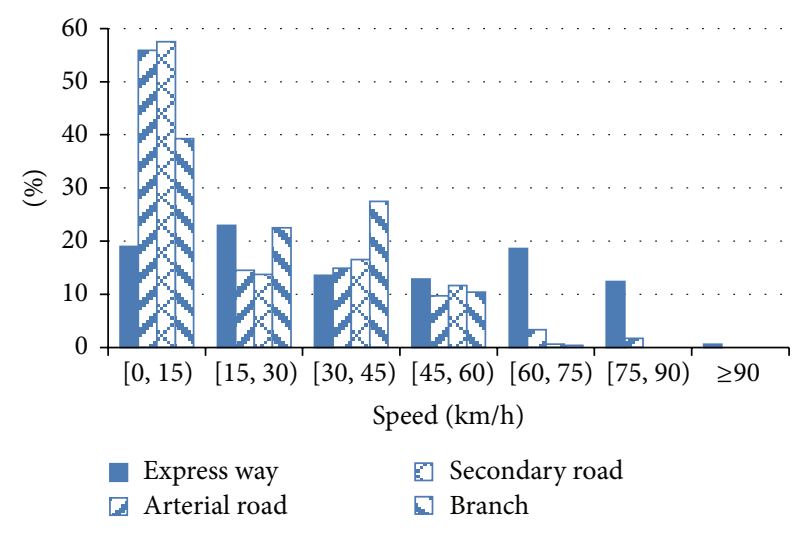

Figure 3: The speed distribution for different road types.

by dividing the average travel speed of EVs into different bins by the step of $3.6 \mathrm{~km} / \mathrm{h}$, all the travelling segments are classified into different speed bins according to their average travel speeds, and the VSP-Bin distributions under all average travel speed bins for different road types are obtained. The average energy consumption rate under each average travel speed bin is estimated as

$$
\overline{\mathrm{EC}_{i}}=\sum_{j} \mathrm{EC}_{j} \times \varphi_{i j}
$$

where $\overline{\mathrm{EC}_{i}}$ refers to the average energy consumption rate for the $i$ th average travel speed bin, kw; $\mathrm{EC}_{j}$ refers to the energy consumption rate for the $j$ th VSP-Bin, $\mathrm{kw} ; \varphi_{i j}$ refers to the percentage of the $j$ th VSP-Bin for the $i$ th average travel speed bin.

Once the energy consumption rate under each average travel speed is obtained, the energy consumption factors for each road type then can be estimated as

$$
\begin{gathered}
V_{i}=\frac{\sum_{k=1}^{n} D_{i k}}{\sum_{k=1}^{n} T_{i k}}, \\
\mathrm{EF}_{i}=\frac{\overline{\mathrm{EC}_{i}} \times \sum_{k=1}^{n} T_{i k}}{\sum_{k=1}^{n} D_{i k}},
\end{gathered}
$$

where $T_{i k}$ refers to the travel time of EV spent in the $k$ th segment of the $i$ th average travel speed bin, h; $D_{i k}$ refers to the mileage of EV during the $k$ th segment of the $i$ th average travel speed bin, $\mathrm{km} ; V_{i}$ refers to the vehicle average travel speed for the $i$ th average travel speed bin, $\mathrm{km} / \mathrm{h} ; \mathrm{EF}_{i}$ refers to the EV's energy consumption factor for the $i$ th average travel speed bin, $\mathrm{kwh} / \mathrm{km}$; $n$ refers to the number of driving segments.

EV's energy consumption factor models for different road types are established using the multiple linear regression approach, and an energy consumption factor is represented by a function of average travel speed [23] as follows:

$$
\mathrm{EF}=\frac{a}{v}+b v+c v^{2}+d,
$$

where $v$ refers to the average travel speed of $\mathrm{EV}, \mathrm{km} / \mathrm{h}$; EF refers to EV's energy consumption factor, $\mathrm{kwh} / \mathrm{km} ; a, b, c$, and $d$ are the coefficients. 


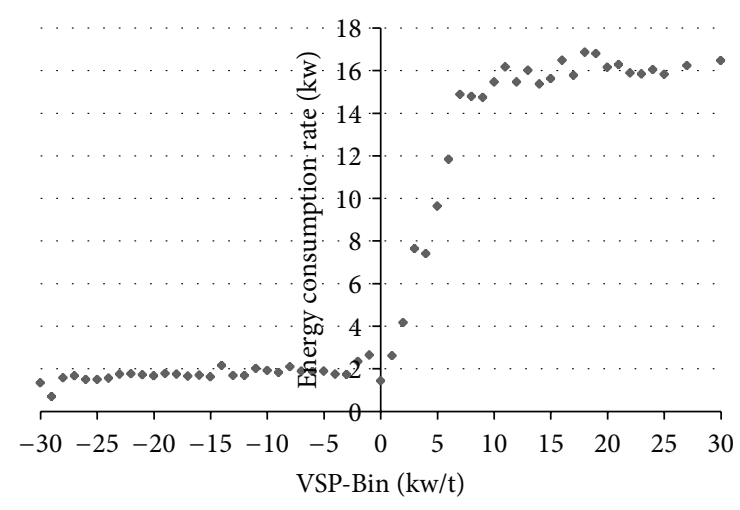

FIGURE 4: Statistics of the energy consumption rates under different VSP-Bins.

\section{Results}

The statistics of the energy consumption rates under different VSP-Bins are shown in Figure 4. The energy consumption rate is low and stable when the VSP-Bin value is negative and increases rapidly as VSP-Bin increases when $0<$ VSP-Bin $<$ 10. However, the rate of increase of the energy consumption rate slows down when VSP-Bin > 10 and approaches zero finally.

On the basis of (2), the VSP-Bin distribution of each average travel speed bin for each road type is calculated. The measured highest average travel speed bin for arterial road, secondary road, and branch is $50.4-54 \mathrm{~km} / \mathrm{h}$ and express way has the highest average travel speed bin of $86.4-90 \mathrm{~km} / \mathrm{h}$. As an example of illustration, eight average travel speed bins of $0 \sim 3.6,7.2 \sim 10.8,14.4 \sim 18,21.6 \sim 25.2,28.8 \sim 32.4,36 \sim$ $39.6,43.2 \sim 46.8$, and $50.4 \sim 54 \mathrm{~km} / \mathrm{h}$ are selected and plotted for demonstrating the general characteristics and variation patterns of VSP-Bin distributions for different road types, as shown in Figure 5. Several characteristics and variation patterns can be observed. (1) For each road type, in the low speed bins, a large percentage of VSP appears in the bin of $0 \mathrm{kw} / \mathrm{t}$. Typical running status of vehicle is idling or queuing around an intersection when VSP-Bin $=0$. (2) Compared to other road types, the percentage of VSP-Bin $=0$ for arterial road is much lower when average travel speed bin is 0-3.6 (Figure 5(a)), mainly owing to the more frequent traffic congestion on arterial road of the road network in Beijing.(3) With the increase of the average travel speed, the VSP-Bin with the highest percentage increases monotonically, and the highest percentage decreases gradually. (4) The graph with the average travel speed more than $21.6-25.2 \mathrm{~km} / \mathrm{h}$ shows characteristics similar to a normal distribution.

Based on the average travel speeds and corresponding measured EV's energy consumption factors calculated by (4), the coefficients of (5) for different road types are calibrated, and the results are shown in Table 2 . All the model coefficients are significantly not zero (absolute t-values exceed 1.96), which indicate that the estimated result are validated. The adjusted $R$-squared for each model is great to indicate a good fit for the EV's energy consumption factor estimation.
TABLE 2: Results of parameters calibration for energy consumption factor models.

\begin{tabular}{|c|c|c|c|c|}
\hline Road type & $\begin{array}{c}\text { Express } \\
\text { way }\end{array}$ & $\begin{array}{c}\text { Arterial } \\
\text { road }\end{array}$ & $\begin{array}{l}\text { Secondary } \\
\text { road }\end{array}$ & Branch \\
\hline \multicolumn{5}{|l|}{ Constant } \\
\hline $\begin{array}{l}\text { Coefficient } \\
(t \text {-value })\end{array}$ & $\begin{array}{c}0.247 \\
(15.271)\end{array}$ & $\begin{array}{c}-0.179 \\
(-2.555)\end{array}$ & $\begin{array}{c}0.21 \\
(16.506)\end{array}$ & $\begin{array}{c}0.208 \\
(24.417)\end{array}$ \\
\hline \multicolumn{5}{|l|}{$v$} \\
\hline $\begin{array}{l}\text { Coefficient } \\
\text { (t-value) }\end{array}$ & $\begin{array}{l}-0.004 \\
(-5.471)\end{array}$ & $\begin{array}{l}0.004 \\
(2.051)\end{array}$ & $\begin{array}{c}-0.001 \\
(-4.067)\end{array}$ & $\begin{array}{c}-0.002 \\
(-6.779)\end{array}$ \\
\hline \multicolumn{5}{|l|}{$v^{-1}$} \\
\hline $\begin{array}{l}\text { Coefficient } \\
(t \text {-value })\end{array}$ & $\begin{array}{c}1.520 \\
(48.387)\end{array}$ & $\begin{array}{c}5.492 \\
(56.861)\end{array}$ & $\begin{array}{c}1.531 \\
(61.547)\end{array}$ & $\begin{array}{c}1.553 \\
(210.891)\end{array}$ \\
\hline \multicolumn{5}{|l|}{$v^{2}$} \\
\hline $\begin{array}{l}\text { Coefficient } \\
(t \text {-value })\end{array}$ & $\begin{array}{c}2.992 E-5 \\
\quad(4.112)\end{array}$ & - & - & $\begin{array}{l}- \\
-\end{array}$ \\
\hline Adjusted $R^{2}$ & 0.996 & 0.997 & 0.998 & 0.999 \\
\hline
\end{tabular}

Note: $v$ is the average travel speed, $\mathrm{km} / \mathrm{h}$.

TABLE 3: Energy consumption factor models.

\begin{tabular}{ll}
\hline Road type & Calculation equation \\
\hline Express way & $\mathrm{EF}=0.247+1.520 / v-0.004 v+2.992 \times 10^{-5} v^{2}$ \\
Arterial road & $\mathrm{EF}=-0.179+0.004 v+5.492 / v$ \\
Secondary road & $\mathrm{EF}=0.21-0.001 v+1.531 / v$ \\
Branch & $\mathrm{EF}=0.208-0.002 v+1.553 / v$ \\
\hline
\end{tabular}

Note: EF is the energy consumption factor, $\mathrm{kwh} / \mathrm{km}$, and $v$ is the average travel speed, $\mathrm{km} / \mathrm{h}$.

The energy consumption factor models for different road types are summarized in Table 3.

From the comparison of energy consumption factors under different average travel speeds for different road types (shown in Figure 6), several characteristics and variation patterns can be observed. (1) The EV's energy consumption factors for express way, secondary road, and branch obey a similar change rule. However, for arterial road, EV's energy consumption factor decreases with the increase of average travel speed and then turns to increase when average travel speed reaches a specified value about $37.1 \mathrm{~km} / \mathrm{h}$. It means that EV travelling on arterial road is the most energy-efficient situation when it travels at the speed of $37.1 \mathrm{~km} / \mathrm{h}$. (2) The energy consumption factor for arterial road is greatly higher than the energy consumption factors for the other three road types when the average travel speed is less than $12 \mathrm{~km} / \mathrm{h}$ and lower than the other three road types when the average travel speed exceeds $12 \mathrm{~km} / \mathrm{h}$. According to above analysis, a conclusion could be drawn that the estimation of EV's energy consumption will be more precise with the road typebased energy consumption factor used in link energy cost calculation in EV's energy-optimal route planning process. 


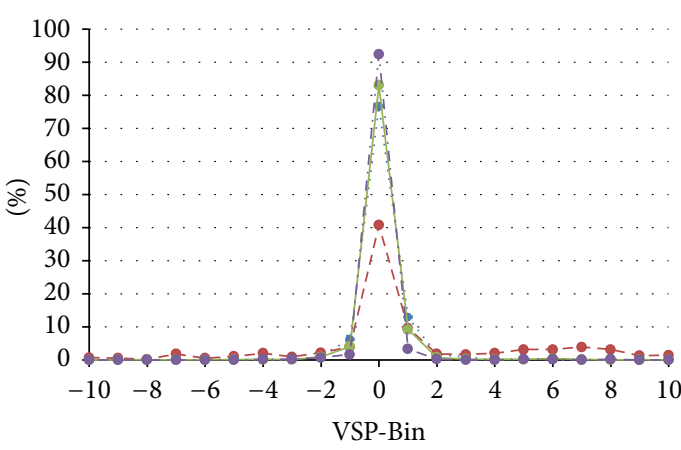

(a) $0 \sim 3.6 \mathrm{~km} / \mathrm{h}$

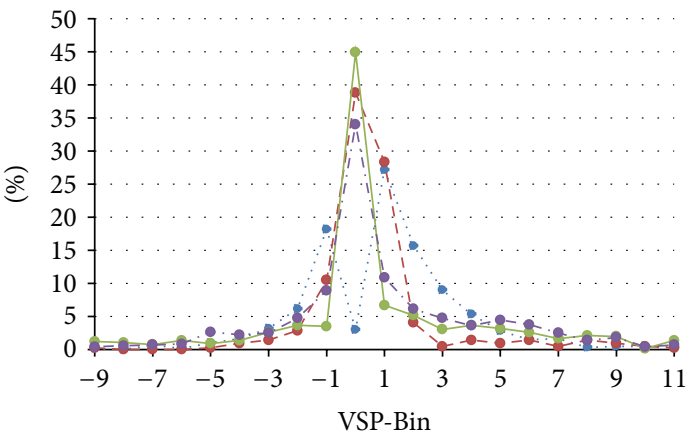

(c) $14.4 \sim 18 \mathrm{~km} / \mathrm{h}$

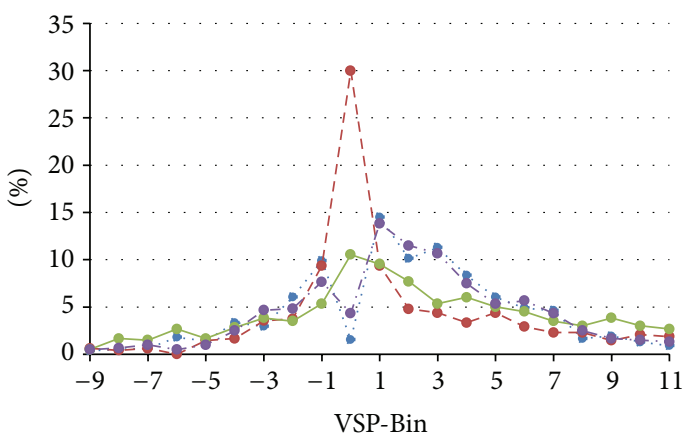

(e) $28.8 \sim 32.4 \mathrm{~km} / \mathrm{h}$

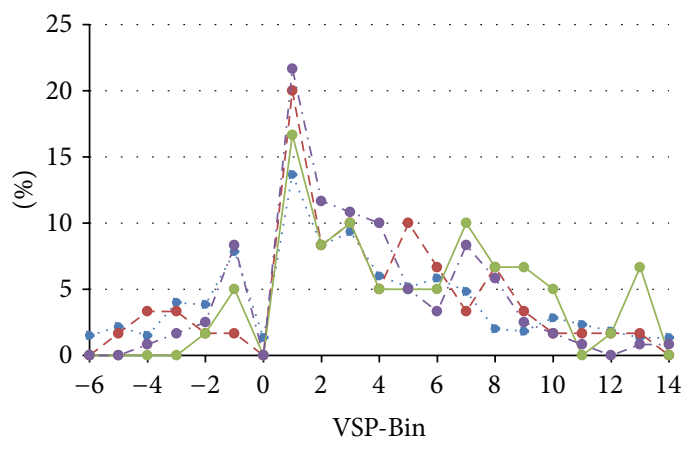

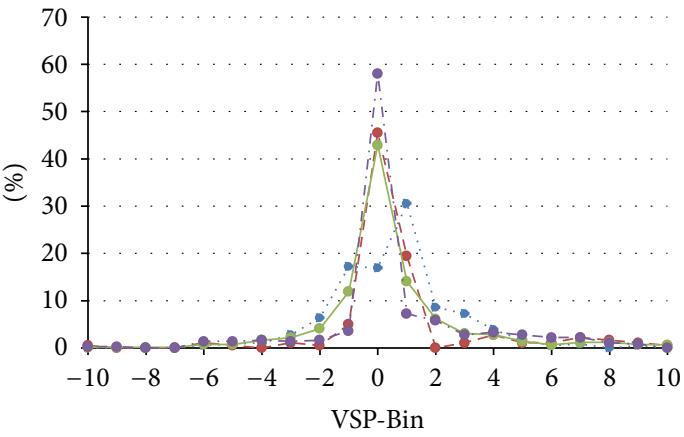

(b) $7.2 \sim 10.8 \mathrm{~km} / \mathrm{h}$

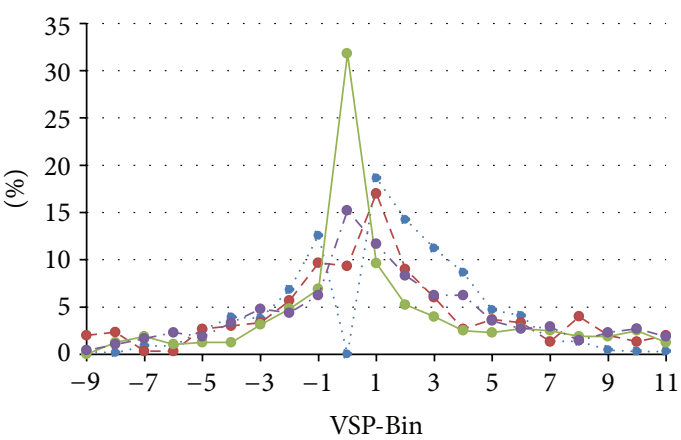

(d) $21.6 \sim 25.2 \mathrm{~km} / \mathrm{h}$

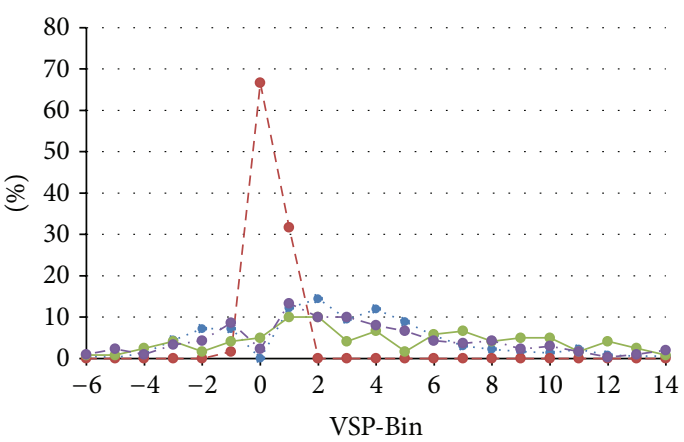

(f) $36 \sim 39.6 \mathrm{~km} / \mathrm{h}$

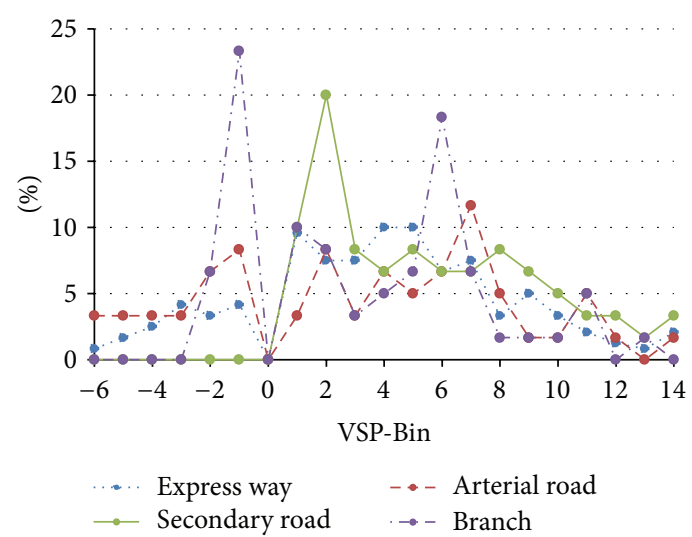

(h) $50.4 \sim 54 \mathrm{~km} / \mathrm{h}$

(g) $43.2 \sim 46.8 \mathrm{~km} / \mathrm{h}$

FIGURE 5: VSP-Bin distributions for different road types. 


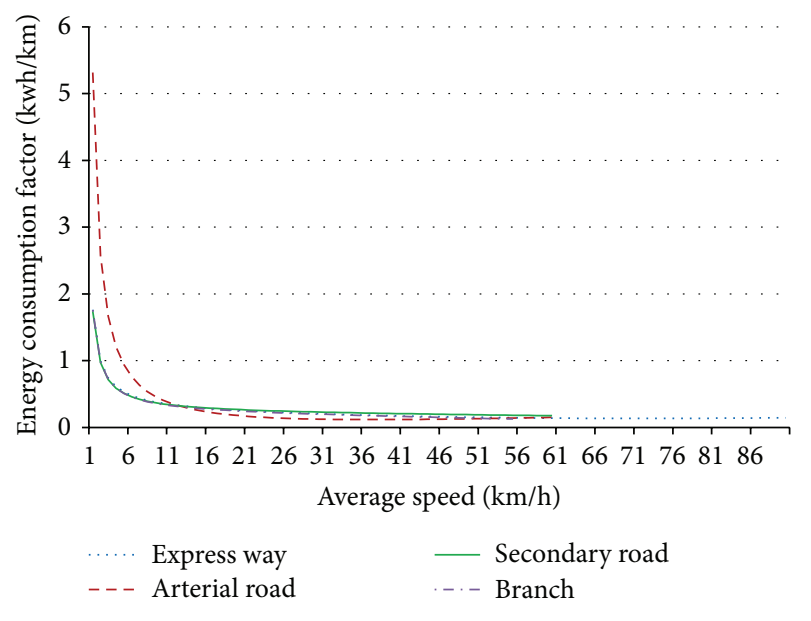

FIGURE 6: Energy consumption factors for different road types.

\section{Conclusions}

This paper presents a methodology for establishing the EV's energy consumption models for different road types. The proposed models are developed through considering the influence of different VSP distribution of different road types on energy consumption, which not only guarantees the accuracy of energy consumption factor models but also makes it possible to estimate the energy consumption for different road types based on current traffic information systems. It can be concluded from the energy consumption factor curves for different road types (shown in Figure 6) that the energy consumption factor of arterial road is notably different from other road types. It is validated that road type-based energy consumption factor should be used in link energy cost calculation in EV's energy-optimal route planning process. In the future practical application, the models presented in this paper can be utilized to forecast EV's cruising range for different road types based on dynamic average travel speed with high accuracy, which can find out the energy-optimal route and reduce the risk of running out of electricity before arriving at the destination or charging station.

\section{Conflict of Interests}

The authors declare that there is no conflict of interests regarding the publication of this paper.

\section{Acknowledgments}

This research is supported by Research Fund for the Doctoral Program of Higher Education of China (no. 20130009110002) and National Natural Science Foundation of China (no. 71210001).

\section{References}

[1] C. Musardo, G. Rizzoni, Y. Guezennec, and B. Staccia, "AECMS: an adaptive algorithm for hybrid electric vehicle energy management," European Journal of Control, vol. 11, no. 4-5, pp. 509-524, 2005.

[2] T. Zuo, E.-J. Yao, Y. Yang et al., "Study on route planning algorithm for electric vehicle," Journal of Beijing Institute of Technology, vol. 21, no. 2, pp. 31-35, 2013.

[3] M. Barth, K. Boriboonsomsin, and A. Vu, "Environmentallyfriendly navigation," in Proceedings of the 10th International IEEE Conference on Intelligent Transportation Systems (ITSC '07), pp. 684-689, Seattle, Wash, USA, October 2007.

[4] K. Boriboonsomsin and M. Barth, "ECO-routing navigation system based on multi-source historical and real-time traffic information," in Proceedings of the IEEE Workshop on Emergent Cooperative Technologies in Intelligent Transportation Systems (ICTSC '10), 2010.

[5] H. Wang, L. Fu, Y. Zhou, and H. Li, "Modelling of the fuel consumption for passenger cars regarding driving characteristics," Transportation Research D, vol. 13, no. 7, pp. 479-482, 2008.

[6] A. G. Simpson, Parametric Modelling of Energy Consumption in Road Vehicles, University of Queensland, St Lucia, Australia, 2005.

[7] D. Brzezinski, C. Hart, and P. Enns, "Final facility-specific speed correction factors," Tech. Rep. EPA-420-R-01-060, U.S, Environmental Protection Agency, Washington, DC, USA, 2001.

[8] Z.-P. Wang, L.-M. Yao, and F.-C. Sun, "Preliminary study on evaluation system of EV energy consumption economy," Transaction of Beijing Institute of Technology, vol. 25, no. 6, pp. 479-486, 2005.

[9] R. Joumard, P. Jost, J. Hickman, and D. Hassel, "Hot passenger car emissions modelling as a function of instantaneous speed and acceleration," Science of the Total Environment, vol. 169, pp. 167-174, 1995.

[10] M. André and C. Pronello, "Relative influence of acceleration and speed on emissions under actual driving conditions," International Journal of Vehicle Design, vol. 18, no. 3-4, pp. 340353, 1997.

[11] Y.-G. Qi, H.-H. Teng, and L. Yu, "Microscale emission models incorporating acceleration and deceleration," Journal of Transportation Engineering, vol. 130, no. 3, pp. 348-359, 2004.

[12] E.-J. Yao, Z-F. Lang, Y.-Y. Song, Y. Yang, and T. Zuo, "Microscopic driving parameters-based energy-saving effect analysis under different electric vehicle penetration," Advances in Mechanical Engineering, vol. 2013, Article ID 435721, 8 pages, 2013.

[13] J. Q. Hansen, M. Winther, and S. C. Sorenson, "The influence of driving patterns on petrol passenger car emission," Science of the Total Environment, vol. 169, pp. 129-139, 1995.

[14] T. Zachariadis and Z. Samaras, "Comparative assessment of European tools to estimate traffic emissions," International Journal of Vehicle Design, vol. 18, no. 3-4, pp. 312-325, 1997.

[15] K. Ahn, H. Rakha, A. Trani, and M. Van Aerde, "Estimating vehicle fuel consumption and emissions based on instantaneous speed and acceleration levels," Journal of Transportation Engineering, vol. 128, no. 2, pp. 182-190, 2002.

[16] J. L. Jiménez-Palacios, Understanding and quantifying motor vehicle emissions with vehicle specific power and TILDS remote sensing [Ph.D. thesis], Massachusetts Institute of Technology (MIT), Cambridge, Mass, USA, 1999.

[17] T. Younglove, G. Scora, and M. Barth, "Designing on-road vehicle test programs for the development of effective vehicle emission models," Transportation Research Record, no. 1941, pp. 51-59, 2005. 
[18] E. K. Nam and R. Giannelli, "Fuel consumption modeling of conventional and advanced technology vehicles in the physical emission rate estimator (PERE)," Tech. Rep. EPA420-P-05-001, Assessment and Standards Division Office of Transportation and Air Quality US Environmental Protection Agency, Washington, DC, USA, 2005.

[19] G.-H. Song and L. Yu, "Estimation of fuel efficiency of road traffic by characterization of vehicle-specific power and speed based on floating car data," Transportation Research Record, no. 2139, pp. 11-20, 2009.

[20] E.-J. Yao and Y.-Y. Song, "Study on eco-route planning algorithm and environmental impact assessment," Journal of Intelligent Transportation Systems, vol. 17, no. 1, pp. 42-53, 2013.

[21] J. Liu and L. Yu, Speed correction model for vehicle emissions and fuel consumption based on VSP distributions [M.S. thesis], Beijing Jiaotong University, Beijing, China, 2010.

[22] G.-H. Song, L. Yu, and Z. Tu, "Distribution characteristics of vehicle-specific power on urban restricted-access roadways," Journal of Transportation Engineering, vol. 138, no. 2, pp. 202209, 2011.

[23] Y. Namikawa, Y. Takai, and N. Ohshiro, Calculation Base of Motor Vehicle Emission Factors, Technical Note of National Institute for Land and Infrastructure Management, 2003. 


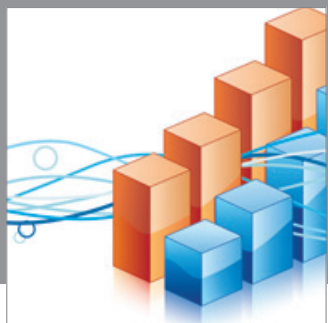

Advances in

Operations Research

mansans

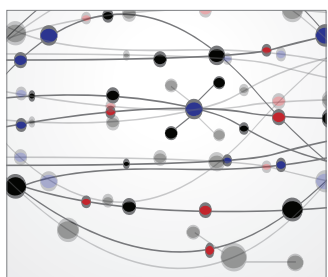

The Scientific World Journal
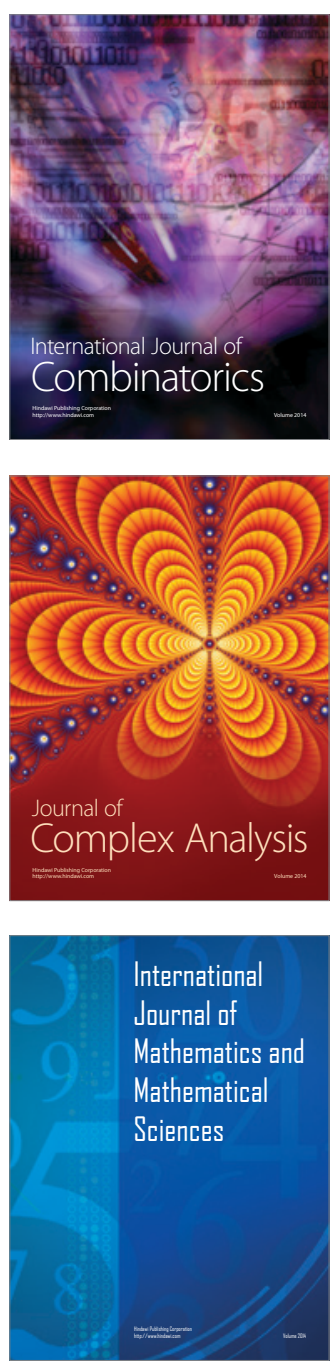
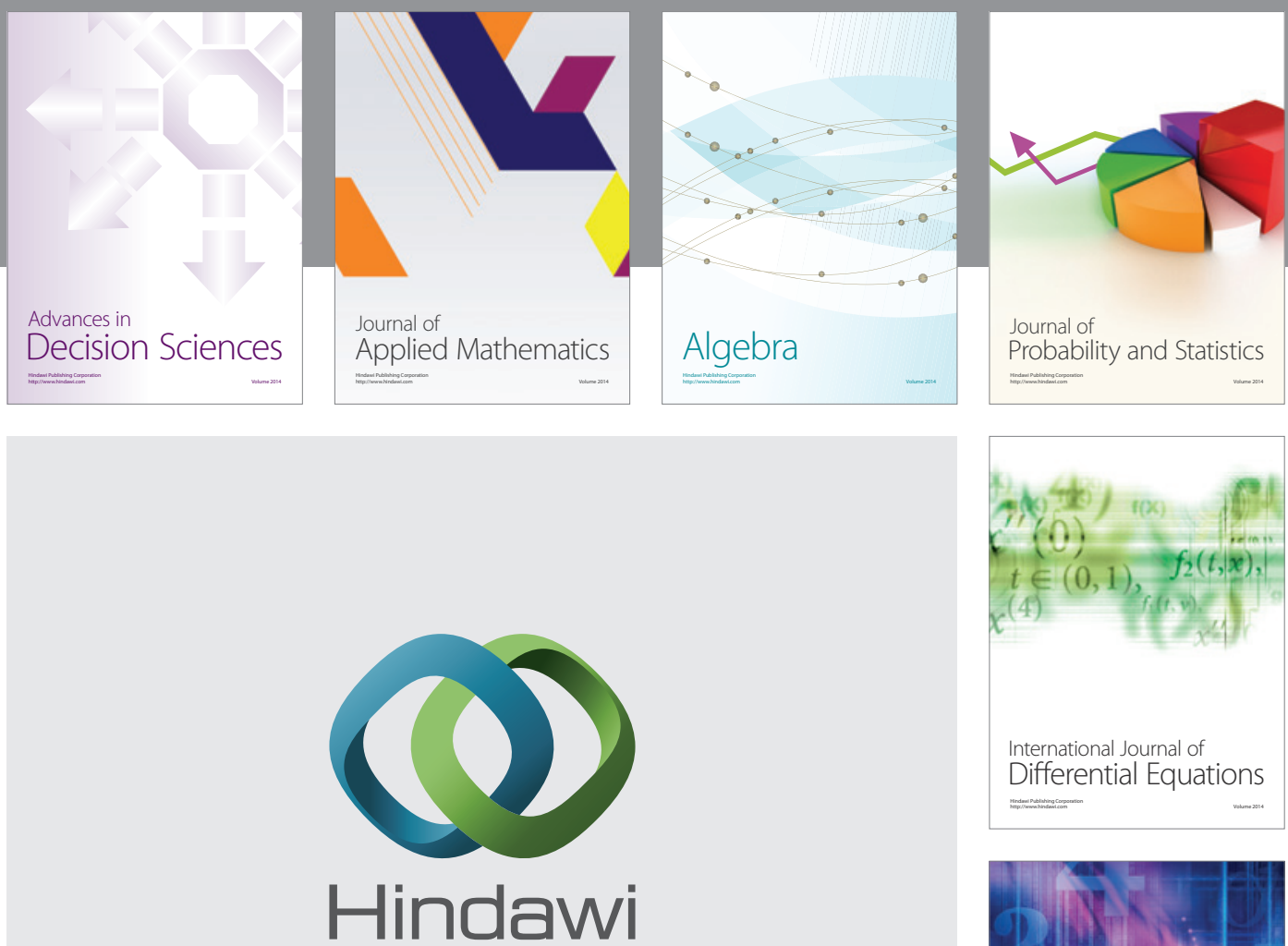

Submit your manuscripts at http://www.hindawi.com
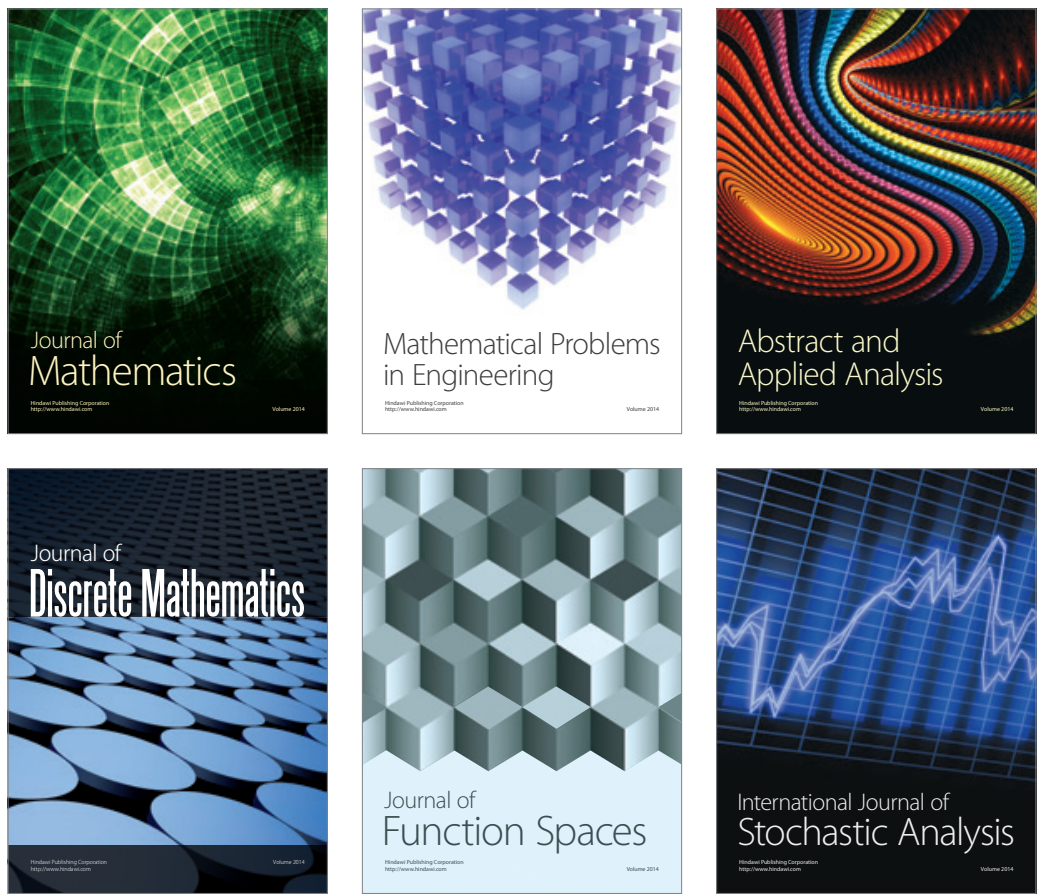

Journal of

Function Spaces

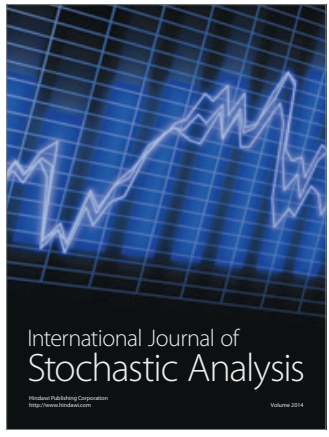

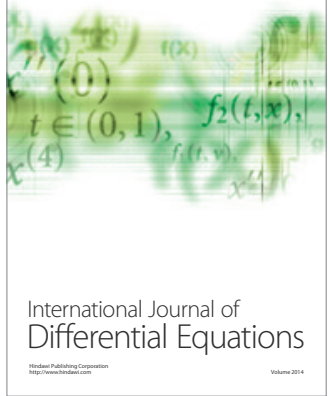
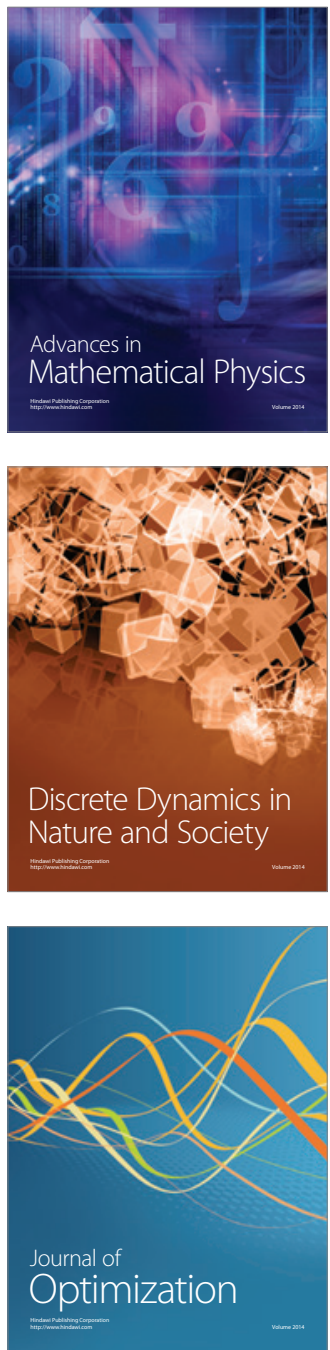